\title{
Use of positional skin distraction method in order to increase sports performance indicators
}

\author{
Elagin Dmitriy Sergeevich \\ Counselor of the Russian Academy of Natural Sciences \\ Russia, St. Petersburg
}

\begin{abstract}
The article discusses the possibilities of positional skin distraction method. A brief description of the method and its theoretical justification are given. A clinical study that proves the effectiveness of the method is presented. The prospects of using the method in high-performance sports, as well as in some areas of medicine, were especially noted.
\end{abstract}

\section{Keywords}

method of positional skin distraction, massage, sports performance, strength endurance, muscle blood supply.

The impetuous development of the sports industry in recent years has led to an active search for methods that can increase human performance indicators. Much attention is paid to the effect on the musculoskeletal system. There is a significant number of manual and hardware massage methods that can qualitatively improve the functional state of muscles [1, 2]. Few modern specialists pay attention to the skin and its functional state. However, in most cases it is the skin that is the main limiting factor for muscle tissue. The role of the skin in the success of sports results is underestimated, which leads to overstrain of the athlete's musculoskeletal system and may cause injuries [3].

As a single organ, the skin performs a large number of functions and has many properties $[4,5]$. The ability to stretch is among others. The muscle tends to change its size during work. The greater the muscular load and the more the athlete's body recruits muscle units, the more significant the changes will be [6]. It is important that the muscle should be able to reach its full potential during work and that as many inhibiting factors as possible should be eliminated. Unfortunately, the skin's ability to stretch decreases with age and it can "limit" muscle stretching, thereby contributing to insufficient vasodilation of intramural muscle vessels, which leads to a more rapid accumulation of metabolic products and the onset of fatigue [7-9].

There are usually 3 layers in the skin: epidermis, dermis and hypodermis. The epidermis consists of a keratinizing epithelial layer, the dermis consists of two successive layers of connective tissue, and the hypodermis is the subcutaneous fatty tissue (SFA) [9-11]. The connective tissue of the dermis contains a large number of collagen and elastin fibers, which 
have the potential to stretch. They are organized into large cords and can extend deep into the muscle fascia and pass into them $[11,12]$. However, the dehydration of the extracellular matrix of the connective tissue that occurs with age can greatly reduce the skin's ability to stretch. Moreover, the processes of dehydration in human skin begin at the age of 20, which indicates the need for the earliest possible exposure to the skin for greater preservation of its potential for stretching [13, 14]. Dmitrii Sergeevich Elagin proposed a method of positional skin distraction (Provisional patent application 63226198, 63235820) to improve the elasticity of the skin in 2021, Having selected a part of the body for action, the skin is stretched and pulled in various positions. A final number of body site positions is formed by a combination of angles of flexion / extension, adduction / abduction, pronation / supination / rotation of adjacent joints. Stretching and retraction of the skin is carried out in 8 main directions, presented in Figures 1a and 16. The implementation of this method is possible with the help of fingers or palms, but the most significant result is achieved with the use of a special massager. It should be noted that the use of a massager not only increases the effectiveness of the method, but also significantly reduces the workload on the specialist.

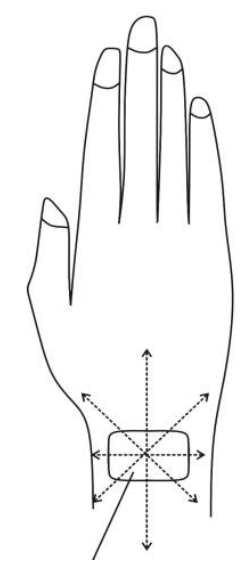

Figure 1a. The main directions of stretching and retraction of the skin.

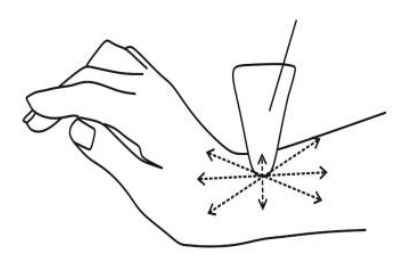

Figure 1b. The main directions of stretching and retraction of the skin.

In the course of stretching and retraction of the skin, the degree of its elasticity is increased by means of "unfixation" (lengthening and micro-tears) of the connective tissue strands between the dermis, the SFA and the muscle fascia. In each new position, there is a redistribution of the tension of the skin, due to the new geometry of the muscle volume and the position of the joints 
[15]. By consistently stretching the skin in all formed positions, one can achieve a significant result for the entire muscle, eliminating the limiting effect of the skin in all its possible working positions.

The mutual influence of the skin and muscle tissue is not limited exclusively to the restrictive influence of one tissue in relation to another. Eliminating excessive skin pressure, the muscle takes an additional volume necessary for its work, which promotes relaxation of intramural muscle vessels and better blood supply to muscle tissue in general, which has a positive effect on its functional state.

Thus, an increase in muscle performance under conditions of physical exertion is justified presumably by three main factors:

- lack of a restrictive effect of the skin on muscle tissue, which allows the body to recruit more muscle fibers and increase the strength of muscle contraction;

- a local increase in muscle blood flow, which makes it possible to increase the delivery of oxygen and nutrients to the working muscle and delay the accumulation of metabolic products that cause the onset of fatigue;

- increased peripheral afferentation in the central nervous system, which contributes to greater recruitment of muscle groups.

The continuity of the observed effect is due to the mechanical effect (stretching, microtears) on the connective tissue cords between the dermis, the SFA and the muscle fascia, and the length of time it takes to return the tissue to an intact state, which causes an increase in the mobility and elasticity of the skin in the selected area of the body for several weeks.

During the implementation of the above method on amateur athletes, static strength endurance significantly increased, the volume of muscles increased, the disappearance of muscle spasms and a decrease in pain were observed.

The study included 10 amateur athletes, candidates for master of sports of Russia in various sports. We studied the static strength endurance (c) of the biceps brachii before and after the massage by the method of positional skin distraction for three sessions. The interval between sessions is 3-4 days. Massage according to the method of positional skin distraction was carried out on the right hand, and classical sports massage was carried out on the left hand of the athletes. The average age of the subjects is 24 years. The weight of the load held by the athletes is $15 \mathrm{~kg}$. To assess the type of distribution of quantitative characteristics, the Shapiro-Wilk test with a critical level of significance of 0.05 was used, and since the distribution of values turned 
out to be different from normal, data analysis was carried out using nonparametric statistical methods. To detect statistical differences between the study groups, both before and after exposure, the Kruskal-Wallis test was used with a critical significance level of 0.05 . The results of the study are presented in tables 1,2 and figure 2 .

Table 1.

Indicators of static strength endurance of the biceps brachii muscle on the right hand before and after massage by the method of positional skin distraction

\begin{tabular}{|c|c|c|c|c|c|c|c|c|c|}
\hline \multirow[t]{2}{*}{ Testee } & \multicolumn{3}{|l|}{ Session 1} & \multicolumn{3}{|l|}{ Session 2} & \multicolumn{3}{|l|}{ Session 3} \\
\hline & $\begin{array}{l}\text { SSE * } \\
\text { before } \\
\text { massage } \\
\text { (c) }\end{array}$ & $\begin{array}{l}\text { SSE * } \\
\text { after } \\
\text { massage } \\
\text { (c) }\end{array}$ & $\begin{array}{l}\text { Growth } \\
(\%)\end{array}$ & $\begin{array}{l}\text { SSE } \\
\text { before } \\
\text { massage } \\
\text { (c) }\end{array}$ & \begin{tabular}{|l} 
SSE \\
after \\
massage \\
(c)
\end{tabular} & $\begin{array}{l}\text { Growth } \\
(\%)\end{array}$ & \begin{tabular}{|l} 
SSE \\
before \\
massage \\
(c)
\end{tabular} & \begin{tabular}{|l} 
SSE \\
after \\
massage \\
(c)
\end{tabular} & $\begin{array}{l}\text { Growth } \\
(\%)\end{array}$ \\
\hline №1 & 65 & 71 & 9 & 69 & 76 & 10 & 76 & 80 & 5 \\
\hline №2 & 51 & 57 & 11 & 57 & 60 & 5 & 59 & 65 & 10 \\
\hline №3 & 42 & 45 & 7 & 45 & 50 & 11 & 47 & 54 & 15 \\
\hline №4 & 41 & 47 & 15 & 46 & 51 & 13 & 50 & 56 & 12 \\
\hline №5 & 38 & 45 & 18 & 43 & 50 & 16 & 48 & 54 & 13 \\
\hline №6 & 49 & 57 & 16 & 57 & 61 & 7 & 59 & 67 & 14 \\
\hline №7 & 50 & 54 & 8 & 54 & 60 & 11 & 57 & 63 & 11 \\
\hline №8 & 61 & 67 & 10 & 65 & 70 & 8 & 69 & 74 & 7 \\
\hline №9 & 39 & 41 & 5 & 40 & 43 & 7 & 41 & 44 & 7 \\
\hline №10 & 47 & 54 & 15 & 52 & 60 & 12 & 59 & 65 & 10 \\
\hline
\end{tabular}

Table 2.

Indicators of static strength endurance of the biceps brachii muscle on the left hand before and after classic sports massage

\begin{tabular}{|l|l|l|l|l|l|l|l|l|l|}
\hline Testee & \multicolumn{3}{|l|}{ Session 1 } & \multicolumn{2}{l|}{ Session 2 } & \multicolumn{2}{l|}{ Session 3 } \\
\cline { 2 - 10 } & SSE & SSE & Growth & SSE & SSE & Growth & SSE & SSE & Growth \\
before & after & $(\%)$ & before & after & $(\%)$ & before & after & $(\%)$ \\
massa & massage & & massage & massage & & massage & massage & \\
& ge (c) & (c) & & (c) & (c) & & (c) & (c) & \\
\hline
\end{tabular}




\begin{tabular}{|l|l|l|l|l|l|l|l|l|l|}
\hline №1 & 63 & 66 & 5 & 63 & 65 & 3 & 64 & 67 & 5 \\
\hline №2 & 52 & 54 & 4 & 53 & 55 & 4 & 53 & 54 & 2 \\
\hline №3 & 43 & 46 & 7 & 43 & 45 & 4 & 44 & 46 & 5 \\
\hline №4 & 41 & 43 & 5 & 43 & 43 & 0 & 44 & 45 & 2 \\
\hline №5 & 36 & 39 & 8 & 38 & 40 & 5 & 38 & 39 & 3 \\
\hline №6 & 50 & 52 & 4 & 51 & 52 & 2 & 51 & 53 & 4 \\
\hline №7 & 54 & 54 & 0 & 53 & 54 & 2 & 54 & 55 & 2 \\
\hline №8 & 57 & 60 & 5 & 58 & 62 & 7 & 58 & 60 & 3 \\
\hline №9 & 37 & 39 & 5 & 39 & 42 & 7 & 39 & 41 & 5 \\
\hline №10 & 45 & 46 & 2 & 45 & 47 & 4 & 46 & 48 & 4 \\
\hline * Note: SSE - static strength endurance &
\end{tabular}

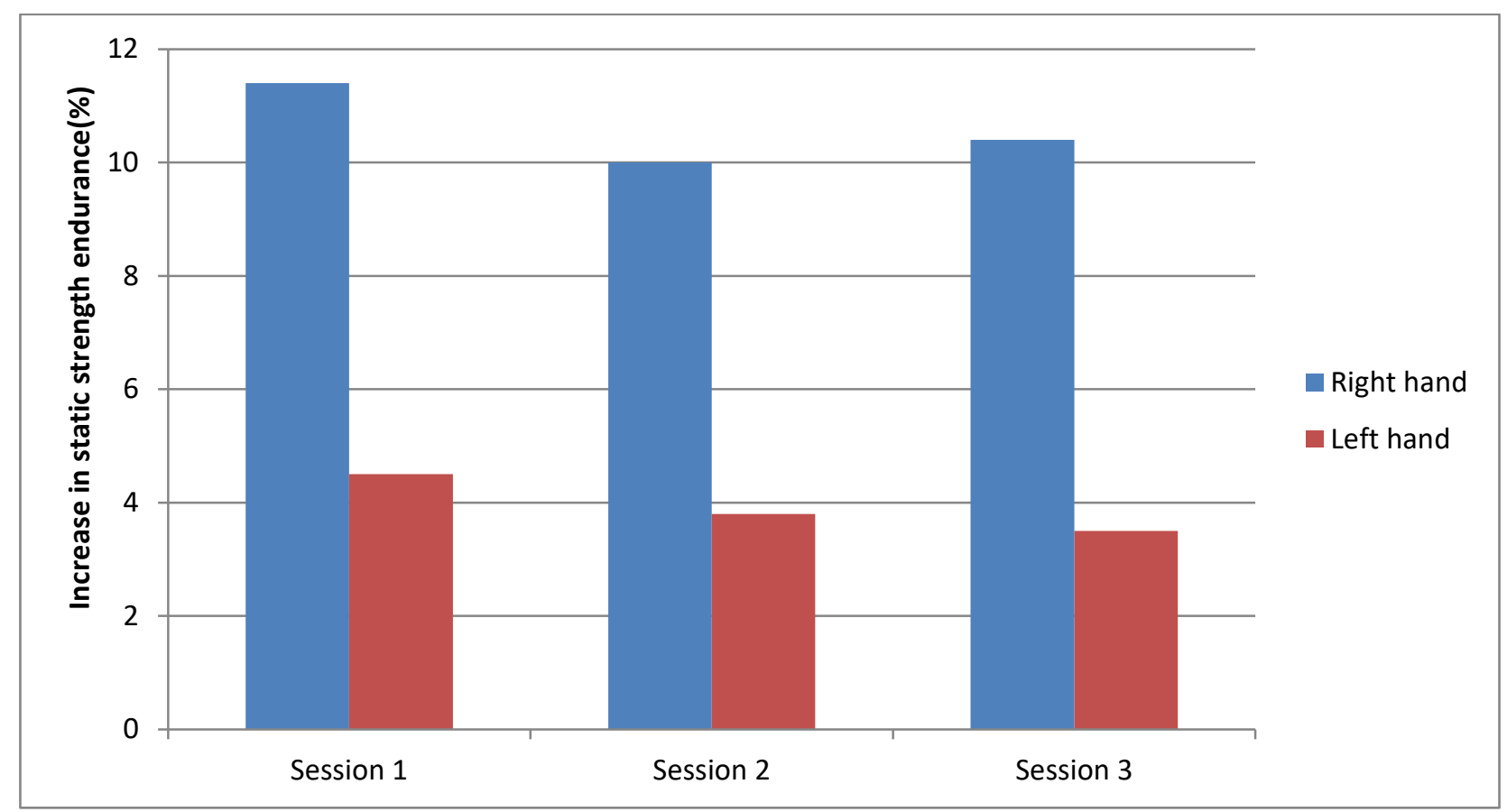

Figure 2. Average increase (\%) in static strength endurance of the right and left biceps brachii during 3 sessions.

After the first session, the increase in static strength endurance in the right hand was $11.4 \%$ versus $4.5 \%$ in the left hand $(\mathrm{p}<0.001)$. After the second session, the increase in static strength endurance in the right arm was $10 \%$ versus $3.8 \%$ in the left arm (p <0.001). After the third session, the increase in static strength endurance in the right hand was $10.4 \%$ versus $3.5 \%$ in the left hand ( $\mathrm{p}<0.001$ ).

Thus, the increase in the long-term performance of the biceps brachii muscle under physical exertion was $34 \%$ on the right arm versus $11 \%$ on the left arm, which is statistically 
significant $(\mathrm{p}<0.001)$ indicates a more pronounced long-term muscle performance achieved by the method of positional skin distraction in comparison with classical sports massage.

The results obtained indicate the high efficiency of the method of positional skin distraction for increasing static strength endurance, which surpasses the efficiency of classical sports massage. The technical simplicity of the method, the ease and speed of training a specialist, the absence of the need for complex equipment for implementation, as well as a high and stable clinical effect - these things open up great prospects for the application of the method in elite sports.

Massage according to the method of positional skin distraction can be used to work out the skin of any part of the body - head, upper and lower extremities, trunk. Since the final main effect of the method is a long-term increase in blood supply to the affected area, the method can be widely used to solve various problems in the field of traumatology and orthopedics, rehabilitation, pulmonology, gastroenterology, dermatology and neurology.

\section{Bibliography}

1. Weerapong P, Hume PA, Kolt GS. The mechanisms of massage and effects on performance, muscle recovery and injury prevention. Sports Med. 2005;35(3):235-56. doi: 10.2165/00007256200535030-00004. PMID: 15730338.

2. Poppendieck W, Wegmann M, Ferrauti A, Kellmann M, Pfeiffer M, Meyer T. Massage and Performance Recovery: A Meta-Analytical Review. Sports Med. 2016 Feb;46(2):183-204. doi: 10.1007/s40279-015-0420-x. PMID: 26744335.

3. Simmons GH, Wong BJ, Holowatz LA, Kenney WL. Changes in the control of skin blood flow with exercise training: where do cutaneous vascular adaptations fit in? Exp Physiol. 2011 Sep;96(9):822-8. doi: 10.1113/expphysiol.2010.056176. Epub 2011 May 20. PMID: 21602295; PMCID: PMC3754812

4. Dąbrowska AK, Spano F, Derler S, Adlhart C, Spencer ND, Rossi RM. The relationship between skin function, barrier properties, and body-dependent factors. Skin Res Technol. 2018 May;24(2):165-174. doi: 10.1111/srt.12424. Epub 2017 Oct 23. PMID: 29057509.

5. Gravitz L. Skin. Nature. 2018 Nov;563(7732):S83. doi: 10.1038/d41586-018-07428-4. PMID: 30464282. 
6. Czerniecki JM, Gitter A. Insights into amputee running. A muscle work analysis. Am J Phys Med Rehabil. 1992 Aug;71(4):209-18. doi: 10.1097/00002060-199208000-00003. PMID: 1642820.

7. Fore J. A review of skin and the effects of aging on skin structure and function. Ostomy Wound Manage. 2006 Sep;52(9):24-35; quiz 36-7. PMID: 16980727.

8. Tobin DJ. Introduction to skin aging. J Tissue Viability. 2017 Feb;26(1):37-46. doi: 10.1016/j.jtv.2016.03.002. Epub 2016 Mar 14. PMID: 27020864.

9. Khavkin J, Ellis DA. Aging skin: histology, physiology, and pathology. Facial Plast Surg Clin North Am. 2011 May;19(2):229-34. doi: 10.1016/j.fsc.2011.04.003. PMID: 21763983.

10. Wong R, Geyer S, Weninger W, Guimberteau JC, Wong JK. The dynamic anatomy and patterning of skin. Exp Dermatol. 2016 Feb;25(2):92-8. doi: 10.1111/exd.12832. Epub 2015 Oct 13. PMID: 26284579.

11. Kanitakis J. Anatomy, histology and immunohistochemistry of normal human skin. Eur J Dermatol. 2002 Jul-Aug;12(4):390-9; quiz 400-1. PMID: 12095893.

12. Kazanci A, Kurus M, Atasever A. Analyses of changes on skin by aging. Skin Res Technol. 2017 Feb;23(1):48-60. doi: 10.1111/srt.12300. Epub 2016 Jun 20. PMID: 27321201.

13. Waller JM, Maibach HI. Age and skin structure and function, a quantitative approach (II): protein, glycosaminoglycan, water, and lipid content and structure. Skin Res Technol. 2006 Aug;12(3):145-54. doi: 10.1111/j.0909-752X.2006.00146.x. PMID: 16827688.

14. Puizina-Ivić N. Skin aging. Acta Dermatovenerol Alp Pannonica Adriat. 2008 Jun;17(2):4754. PMID: 18709289.

15. Alexander RM. Muscle geometry. J Physiol. 1998 Oct 15;512 ( Pt 2)(Pt 2):315. doi: 10.1111/j.1469-7793.1998.315be.x. PMID: 9763620; PMCID: PMC2231200. 